\title{
Alumina-supported Tri-rhenium Clusters Revealed by Aberration-corrected Electron Microscopy
}

\author{
V. A. Bhirud, ${ }^{*}$ M. J. Moses, ${ }^{* *}$ D. A. Blom, ${ }^{* *}$ L. F. Allard, ${ }^{* *}$ T. Aoki, ${ }^{* * *}$ S. Mishina, ${ }^{* * *}$ C. K. Narula, ${ }^{* *}$ \\ and B. C. Gates* \\ *Dept. of Chemical Engineering and Materials Science, Univ. of California, Davis, CA 95616, USA \\ **Metals and Ceramics Division, Oak Ridge National Laboratory, Oak Ridge, TN 37831, USA \\ ** JEOL USA, 11 Dearborn Rd., Peabody, MA 01960, USA
}

The success of aberration-correcting (AC) electron optics has enabled the imaging and analysis of individual nanoparticles of catalytic metals dispersed on porous supports by scanning transmission electron microscopy (STEM) and electron energy loss spectroscopy (EELS), which in combination with catalyst testing and X-ray absorption and IR spectroscopies, may lead to a new fundamental understanding of microstructure-catalytic activity relationships. Here we present AC-STEM images and X-ray absorption spectroscopy of tri-rhenium carbonyl clusters supported on porous $\gamma-\mathrm{Al}_{2} \mathrm{O}_{3}$. The sample was chosen because similar catalysts are active for important reactions including olefin metathesis, hydrocarbon reforming, and cycloalkane ring opening, as reported recently [1].

Tri-rhenium $\left(\mathrm{Re}_{3}\right)$ carbonyl clusters with a triangular framework of $\mathrm{Re}$ atoms, $\mathrm{H}_{3} \mathrm{Re}_{3}(\mathrm{CO})_{12}$, were supported on $\gamma-\mathrm{Al}_{2} \mathrm{O}_{3}$ [Degussa]. The $\gamma-\mathrm{Al}_{2} \mathrm{O}_{3}$ was initially mixed with deionized water, and the slurry was dried for $24 \mathrm{~h}$ at $393 \mathrm{~K}$, followed by calcination at $773 \mathrm{~K}$ in flowing $\mathrm{O}_{2}$ for $2 \mathrm{~h}$ and evacuation for $14 \mathrm{~h}$. A solution of $\mathrm{H}_{3} \mathrm{Re}_{3}(\mathrm{CO})_{12}$ [2] in $n$-pentane was brought into contact with the partially dehydroxylated $\gamma-\mathrm{Al}_{2} \mathrm{O}_{3}$ support with exclusion of air and moisture. The pentane solvent was removed by evacuation to provide samples containing $1 \mathrm{wt} \% \operatorname{Re}[3]$. Because the supported clusters are highly reactive, the TEM sample preparation and introduction into the microscope were carried out under inert atmospheres.

IR spectra of the precursor adsorbed on $\gamma-\mathrm{Al}_{2} \mathrm{O}_{3}$ almost match that reported for $\mathrm{H}_{3} \mathrm{Re}_{3}(\mathrm{CO})_{12}$, indicating the presence of the intact precursor on the support. Extended X-ray absorption fine structure (EXAFS) spectra indicate a Re-Re contribution with coordination number of 2.1 at a distance of $3.25 \AA$, consistent with the triangular Re framework. The Re-CO contributions also agree with the identification of $\mathrm{H}_{3} \mathrm{Re}_{3}(\mathrm{CO})_{12}$.

STEM images of the supported clusters are shown in the figures. The level of phase contrast present in the bright field mode is illustrated in Fig. 1. A high degree of phase contrast on the bare $\gamma-\mathrm{Al}_{2} \mathrm{O}_{3}$ support is evident in the bright-field STEM mode compared to that in the high-angle annular darkfield (HA-ADF or Z-contrast) STEM mode. This precludes the unambiguous identification of Re atoms and clusters of $\mathrm{H}_{3} \mathrm{Re}_{3}(\mathrm{CO})_{12} / \gamma-\mathrm{Al}_{2} \mathrm{O}_{3}$, when viewed in bright-field STEM mode. However, a similar sample area in a HA-ADF image of a Re-loaded specimen shows clearly discernible Re atoms and clusters (Fig. 2a). Two tri-rhenium raft-like clusters can be located in Fig 2b. $\mathrm{A} \mathrm{Re}_{3}$ cluster is shown circled, with inset at higher magnification. This appears to be a cluster tethered to an alumina facet lying normal to the beam direction. The square area indicated in Fig. $2 \mathrm{~b}$ is shown in Fig. 3, along with two line profiles and a model structure. The intensity profile suggests that the spot of double intensity corresponds to two Re atoms aligned along the beam direction, in a $\operatorname{Re}_{3}$ cluster tethered to a ledge that is parallel to the beam direction, as shown in the schematic [4]. 


\section{References}

[1] F.S. Modica, S.R. Bare, G. E. Mickelson, J. J. Rehr, A. L. Ankudinov, $18^{\text {th }}$ North American Catalysis Society Meeting, Cancun, Mexico, 232 (2003).

[2] M.A. Andrews, S. W. Kirtley, H. D. Kaesz, Inorg. Synth. 17 (1977) 16.

[3] A. S. Fung, P. A. Tooley, M. J. Kelley, D. C. Koningsberger, B. C. Gates, J. Phys. Chem. 95 (1991) 225.

[4] Work sponsored by Heavy Vehicle Propulsion Materials Program, Office of FreedomCAR and Vehicle

Technology, U.S. Department of Energy, under contract DE-AC05-00OR22725 with UT-Battelle, LLC.

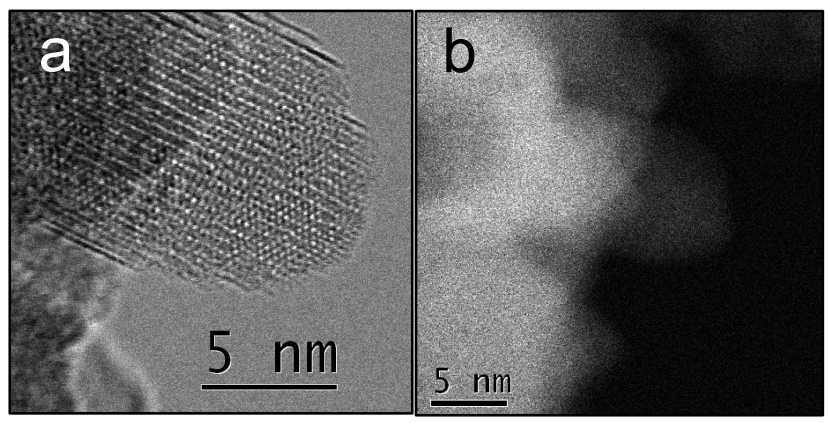

FIG. 1. a) Bright-field STEM image of treated bare $\gamma-\mathrm{Al}_{2} \mathrm{O}_{3}$, showing high phase contrast. b) Dark-field STEM image of similar area, showing lack of phase contrast.

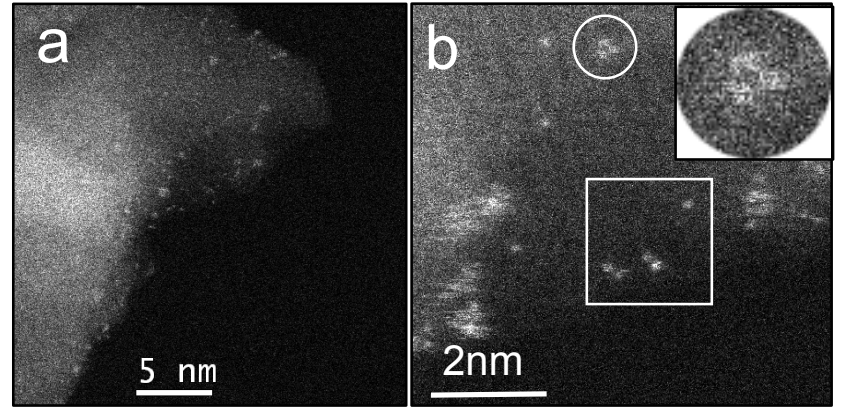

FIG. 2. a) ADF image of $\mathrm{H}_{3} \mathrm{Re}_{3}(\mathrm{CO})_{12} / \gamma-\mathrm{Al}_{2} \mathrm{O}_{3}$, at same magnification as Fig. 1b, showing Re atoms and clusters in bright contrast. b) Higher magnification image with a $\mathrm{Re}_{3}$ cluster circled; box is shown in detail in Fig. 3.
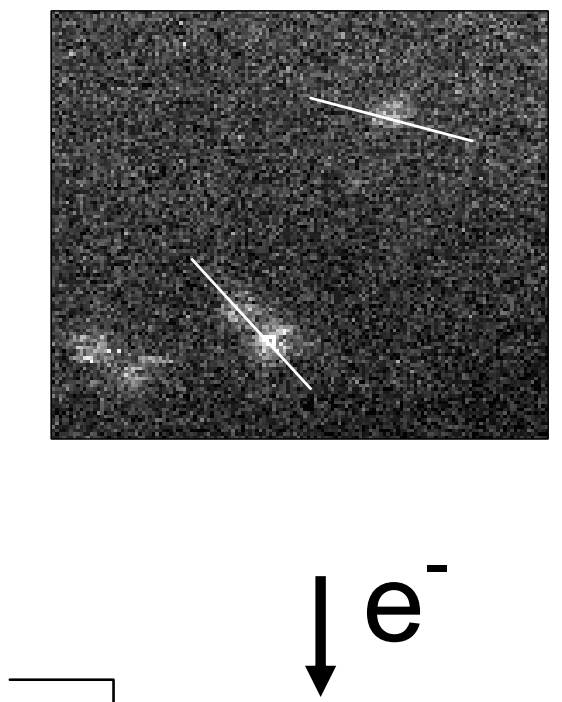
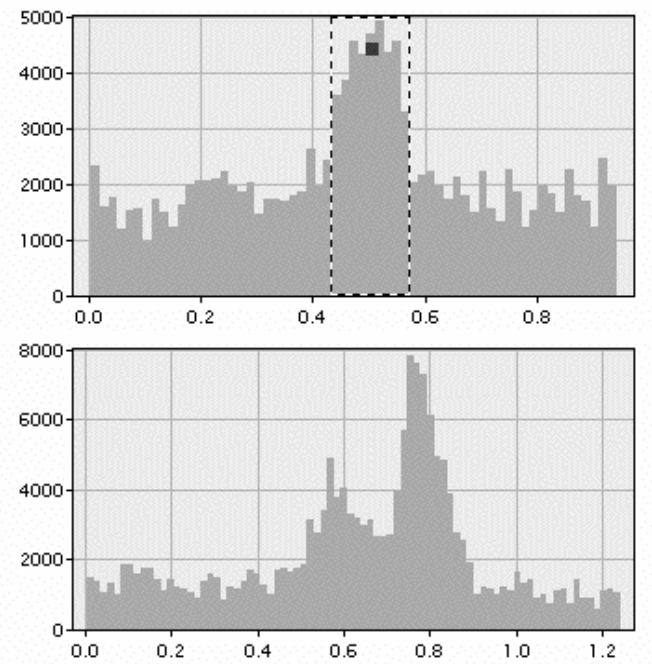

FIG. 3. Intensity profiles of single atom and apparent 3atom cluster seen edge-on, as depicted in the schematic. The cluster may be tethered to a ledge on the support that is parallel to the beam direction. 